\title{
Endoscopic findings of indolent systemic mastocytosis involving the colon
}

A 64-year-old Japanese woman visited our hospital in July 2013 with a complaint of intermittent abdominal pain for 1 month. She had a history of maculopapular rashes on the neck over a period of 14 years. Colonoscopy using indigo carmine dye spraying revealed a few yellowish-white polypoid lesions ( Fig. 1 a,b) and yellowish-white nodular or granular mucosal lesions in the ascending colon ( $\bullet$ Fig. 1 c) and the cecum ( $\bullet$ Fig. $1 \mathrm{~d}$ ).

Histological examination of the biopsy specimens taken from the bowel lesions revealed marked mast cell infiltration with prominent eosinophils in the lamina propria ( Fig. 2a,b). The mast cells were highlighted by immunostaining for KIT ( $\bullet$ Fig. 2c). Histology of biopsy specimens taken from the maculopapular rash on the neck also confirmed increased mast cells in the lamina propria, which were again highlighted by KIT ( $\bullet$ Fig. 2 d).

On the basis of these findings, we diagnosed the patient as having indolent systemic mastocytosis involving the colon and skin. No evidence of mast cell infiltration was found in the bone marrow. We treated the patient with oral histamine receptor 1 and 2 antagonists. The medications resulted in prompt resolution of her abdominal pain and the maculopapular rash on her neck.

Systemic mastocytosis is a rare disease characterized by a clonal neoplastic proliferation of mast cells that accumulate in the bone marrow, skin and/or other extracutaneous organs, such as the gastrointestinal tract [1]. Several reports of systemic mastocytosis involving the colon have been described in Western countries [25]. In these reports, nodular mucosal lesions [2,4,5], multiple areas of pigmentation [3], polypoid lesions [4], aphthous ulcers, erosions [4], granularity, erythe-
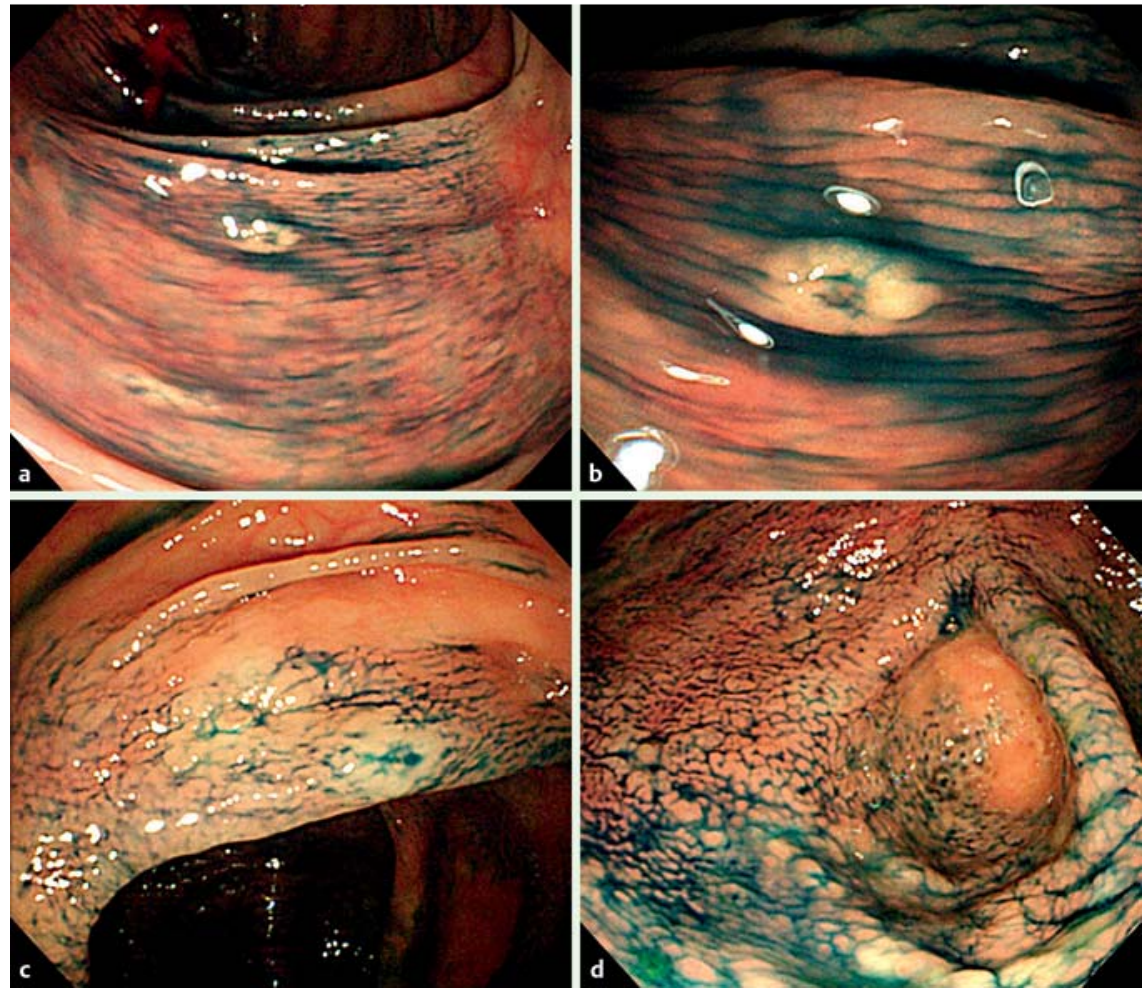

Fig. 1 Colonoscopic views in a 64-year-old Japanese woman who had a long history of maculopapular rashes on the neck and a 1-month history of intermittent abdominal pain showing: $\mathbf{a}$ a few yellowishwhite polypoid lesions in the ascending colon, with; $\mathbf{b}$ a shallow depression in the center; $\mathbf{c}$ nodular mucosal lesions in the ascending colon; $\mathbf{d}$ nodular mucosal lesions in the cecum.

ma, and even normal-appearing mucosa $[4,5]$ have been described as the characteristic endoscopic findings of systemic mastocytosis involving the colon. To the best of our knowledge, this is the first report of systemic mastocytosis involving the colon in a Japanese patient.

\section{Endoscopy_UCTN_Code_CCL_1AD_2AJ}

Competing interests: None

\section{Shuji Kochi ${ }^{1}$, Shotaro Nakamura ${ }^{2}$, Yumi Oshiro ${ }^{3}$, Koichi Kurahara', Keisuke Kawasaki ${ }^{1}$, Hiroki Yaita', Tadahiko Fuchigami ${ }^{1}$}

${ }^{1}$ Division of Gastroenterology, Matsuyama Red Cross Hospital, Ehime, Japan

2 Department of R/D for Surgical Support System, Center for Advanced Medical Innovation, Kyushu University, Fukuoka, Japan

${ }^{3}$ Department of Pathology, Matsuyama Red Cross Hospital, Ehime, Japan 


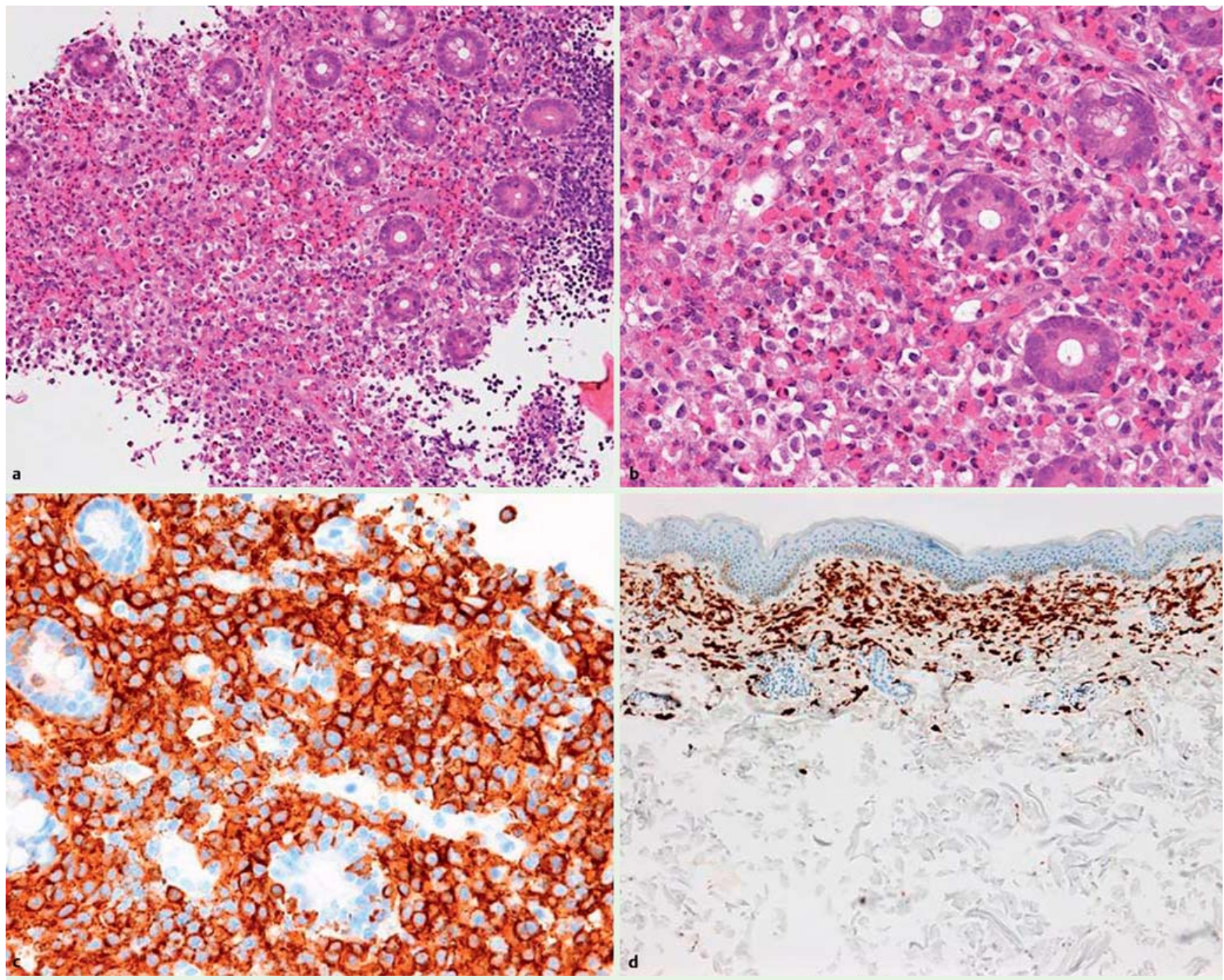

Fig. 2 Histological findings of the biopsy specimens. a, b, $\mathbf{c}$ Biopsy of one of the colonic lesions showing mast cell infiltration with eosinophils in the lamina propria: a stained with hematoxylin and eosin $(\mathrm{H} \& \mathrm{E})$, original magnification $\times 20$; b stained with H\&E, original magnification $\times 40$; $\mathbf{c}$ immunostained for $\mathrm{KIT}$, which highlights the mast cells, original magnification $\times 40$. $\mathbf{d}$ Biopsy of the skin lesion showing increased mast cells in the lamina propria that are highlighted by the KIT immunostain (original magnification $\times 20$ ).

\section{References}

1 Swerdlow SH, Campo E, Harris NL et al. WHO Classification of Tumours of Haematopoietic and Lymphoid Tissues. 4th ed. Lyon, France: IARC Press; 2008: 54-63

2 Lee JK, Whittaker SJ, Enns RA et al. Gastrointestinal manifestations of systemic mastocytosis. World J Gastroenterol 2008; 14: $7005-7008$

3 Scolapio JS, Wolfe J 3rd, Malavet P et al. Endoscopic findings in systemic mastocytosis. Gastrointest Endosc 1996; 44: 608-610
4 Kirsch $R$, Geboes $K$, Shepherd NA et al. Systemic mastocytosis involving the gastrointestinal tract: clinicopathologic and molecular study of five cases. Mod Pathol 2008; $21: 1508-1516$

5 Doyle LA, Sepehr GJ, Hamilton MJ et al. A clinicopathologic study of 24 cases of systemic mastocytosis involving the gastrointestinal tract and assessment of mucosal mast cell density in irritable bowel syndrome and asymptomatic patients. Am J Surg Pathol 2014; 38: $832-843$

\section{Bibliography}

DOI http://dx.doi.org/

10.1055/s-0034-1390916

Endoscopy 2014; 46: E678-E679

(c) Georg Thieme Verlag KG

Stuttgart · New York

ISSN 0013-726X

Corresponding author

Shuji Kochi, MD

Division of Gastroenterology

Matsuyama Red Cross Hospital

1 Bunkyo-cho, Matsuyama-shi

Ehime 790-8524

Japan

Fax: +81-89-9269916

decorin@intmed2.med.kyushu-u.ac.jp 